\title{
Development of the lateral displacement crushable stopper, a part of bogie for countermeasures against derailment in case of earthquake and influence of repeated loading during usual run on moving load
}

\author{
Daichi NAKAJIMA*, Mitsugi SUZUKI *, Yukio NISHIYAMA *, Takefumi MIYAMOTO * \\ and Yasushi KAJITANI ** \\ * Railway Technical Research Institute \\ 2-8-38 Hikari-cho, Kokubunji-shi, Tokyo 184-8540, Japan \\ E-mail: nakajima@rtri.or.jp \\ ** Research \& Development Center of JR East Group, East Japan Railway Company \\ 2-479 Nisshin-cho, Kita-ku, Saitama-shi, Saitama 331-8513, Japan
}

Received: 29 July 2016; Revised: 6 January 2017; Accepted: 29 January 2017

\begin{abstract}
It is known that the center pin of a car body strikes strongly against the lateral displacement stopper of the bogie when the vehicle vibrates widely in the case of earthquake motion with a predominant frequency of over 1.4 Hz. During such movement, and due to considerably large wheel/rail lateral force and bogie rolling, etc., there is a risk of the wheel jumping to a height above the wheel flange, which in turn may result in derailment. It is thought that larger gap between the lateral displacement stopper and the center pin will improve running safety by buffering the strong impact against the lateral displacement stopper and because of a better vibration-damping effect of the lateral damper. Running safety effectively improves using a specially designed anti-seismic lateral damper which can provide large damping forces during a major earthquake. Accordingly, in this research, for the purpose of improving running safety in the case of an earthquake, a crushable lateral displacement stopper was developed with the same nominal gap from the center pin as currently used devices, in the normal condition, but which can expand in the case of a strong impact due to a large earthquake, in order to ensure vehicle running stability and quality. The crushable stopper is designed to be used together with a specially designed anti-seismic lateral damper. RTRI developed a mechanical crushable stopper with a mechanical fuse for the movable mechanism in order to expand gap in abnormal conditions, in such major earthquake. The seat of the lateral displacement stopper rubber gets displaced in the same direction as the expanding gap, if a predetermined load (a set moving load) acts on the stopper. Moreover, repeated loading test was carried out to confirm the influence of the repeated loading during usual operation.
\end{abstract}

Key words : Earthquake, Derailment, Bogie, Lateral displacement stopper, Crushable stopper, Shaking test

\section{Introduction}

It is known that the center pin of a car body strikes strongly against the lateral displacement stopper of the bogie when the vehicle vibrates widely in the case of earthquake motion with a predominant frequency of over $1.4 \mathrm{~Hz}$. During such movement, and due to considerably large wheel/rail lateral force and bogie rolling, etc., there is a risk of the wheel jumping to a height above the wheel flange, which in turn may result in derailment. Larger gap between the lateral displacement stopper and the center pin can improve running safety by buffering the strong impact against the lateral displacement stopper which achieves a better vibration-damping effect of the lateral damper (Miyamoto and Ishida, 2008). Running safety also can be effectively improved (Miyamoto and Ishida, 2008) by using a specially designed anti-seismic lateral damper which provides large damping force during a major earthquake (Iida, et al., 2012). 
Accordingly, in this research, for the purpose of improving running safety in the case of a major earthquake, a crushable lateral displacement stopper was developed with the same nominal gap as currently used devices, in the normal condition, but which can expand in the case of a strong impact due to a large earthquake, in order to ensure vehicle running stability and quality. The crushable stopper is designed to be used together with a specially designed anti-seismic lateral damper. This paper is based upon (Nakajima et al., 2015), but the current paper includes the following additional research: repeated loading test.

\section{Outline of the crushable stopper}

RTRI developed a mechanical crushable stopper with a mechanical fuse for the movable mechanism in order to expand gap in abnormal conditions, in such a major earthquake. The seat of the lateral displacement stopper rubber gets displaced in the direction of gap expansion, if a predetermined load (a set moving load) acts on the stopper. Two pairs of mechanical crushable stoppers with predetermined movement loads of $40 \mathrm{kN}$ and $80 \mathrm{kN}$ were produced to test the reliability of the stopper movement.

Although a hydraulic crushable stopper designed with a hydraulic circuit for the movable mechanism was also developed, this paper only describes the development of the mechanical crushable stopper.

Figure 1 is a conceptual diagram showing the motion of the mechanical crushable stopper. A nominal gap is maintained in normal conditions, with internal and outer cylinders with mechanical fuse. When force in excess of the predetermined load is exerted onto the stopper, the mechanical fuses fracture, displacing the internal cylinder and allowing the gap to expand by $50 \mathrm{~mm}$. Repeated use is possible by replacing the mechanical fuses.

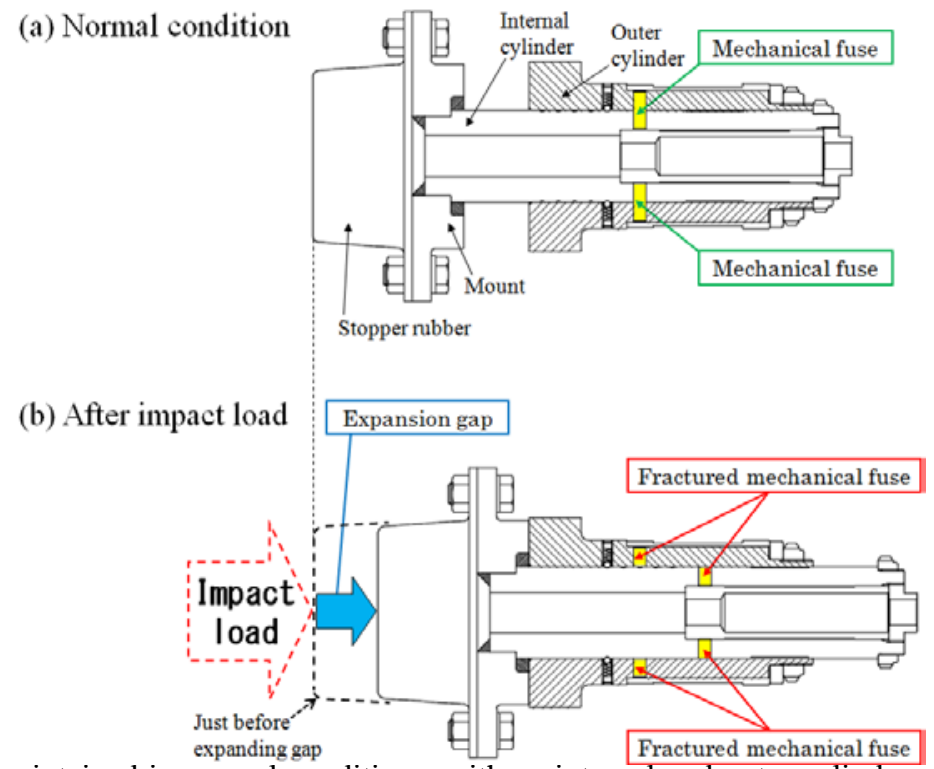

Fig. 1 Nominal gap is maintained in normal conditions, with an internal and outer cylinder with mechanical fuse. When force in excess of the set moving load is exerted onto the stopper, the mechanical fuses fracture, displacing the internal cylinder and allowing the gap to expand by $50 \mathrm{~mm}$.

Figure 2 shows the outside view of the mechanical crushable stopper. Figure 3 shows the mechanical fuse. The shape of the mechanical crushable stopper is same for both set moving loads of $40 \mathrm{kN}$ and $80 \mathrm{kN}$. The overall length is $414 \mathrm{~mm}$ (including the stopper rubber). The maximum diameter of the cylinder is $110 \mathrm{~mm}$, the height $144 \mathrm{~mm}$ and the width $220 \mathrm{~mm}$. The weight is about $28 \mathrm{~kg}$ (including the stopper rubber). Brass is used for the mechanical fuses and four

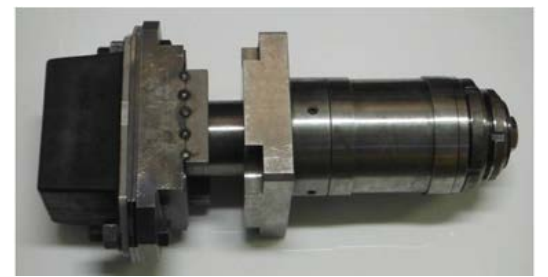

Fig. 2 Outside view of the mechanical crushable stopper is same for both set moving loads of $40 \mathrm{kN}$ and $80 \mathrm{kN}$.

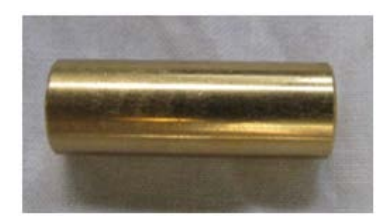

Fig. 3 Brass is used and four mechanical fuses are installed. The diameter is $7 \mathrm{~mm}$ for a set moving load of $40 \mathrm{kN}$ and $10 \mathrm{~mm}$ for $80 \mathrm{kN}$. 
mechanical fuses are installed. The diameter of the mechanical fuse depends on the set moving load. The diameter of the mechanical fuse is $7 \mathrm{~mm}$ for a set moving load of $40 \mathrm{kN}$ and $10 \mathrm{~mm}$ for $80 \mathrm{kN}$.

\section{Static load test}

In order to confirm the basic performance of the crushable stopper, static load tests were carried out.

\subsection{Test method}

Figure 4 shows the static load test apparatus including a gate type press. Loading was slowly carried out on the crushable stopper with a manual hydraulic jack until the mechanical fuse fractured, and the loading force and the displacement of the moving part (internal cylinder) were measured.

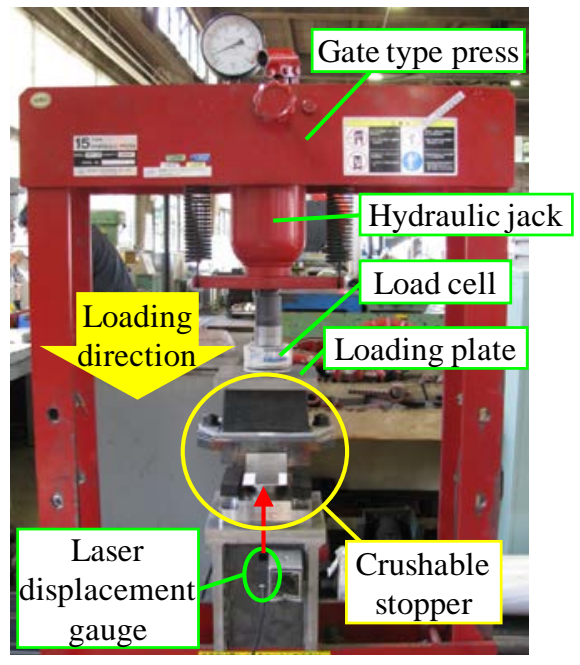

Fig. 4 Static load tests were carried out with the static load test apparatus including a gate type press. Loading was slowly carried out on the crushable stopper with a manual hydraulic jack until the mechanical fuse fractured, and the loading force and the displacement of the moving part (internal cylinder) were measured.

\subsection{Results of the test}

Figures 5 and 6 show examples of the measurement results for two levels of set moving loads. Moreover, full test results are shown in Table 1 . Here, the presumed breaking load was calculated in consideration of the material and the diameter of the mechanical fuse, using an experimental equation found beforehand. The equation was established on the basis of verification tests, on the movement of the mechanical fuse by a fundamental experimental model, which were carried out 10 times for each fuse diameter to confirm stability of movement. Although the $80 \mathrm{kN}$ set moving load is larger than the presumed breaking load by about ten percent, the dispersion in measured values in both set moving loads of $40 \mathrm{kN}$ and $80 \mathrm{kN}$ was small. These results confirm the stability of the crushable stopper motion.

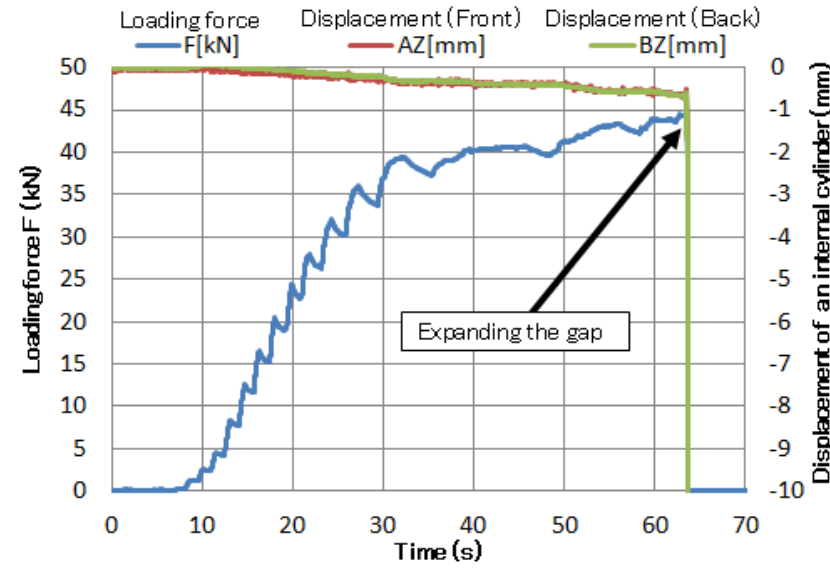

Fig. 5 Example of a measurement result (set moving load is $40 \mathrm{kN})$.

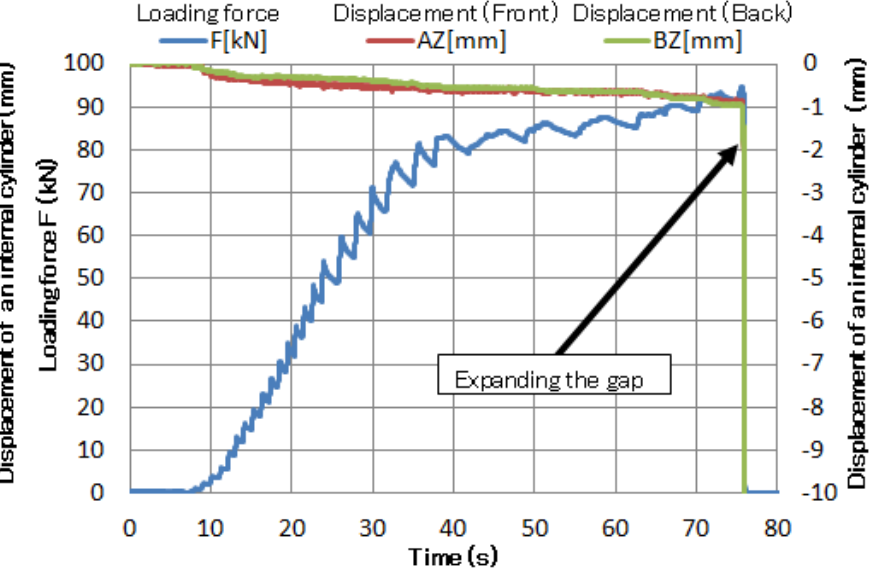

Fig. 6 Example of a measurement result (set moving load is $80 \mathrm{kN}$ ). 
Table 1 Result of the static load test.

\begin{tabular}{c|c|c|c|c|c||c}
\hline \hline \multirow{2}{*}{$\begin{array}{c}\text { Set moving } \\
\text { load }[\mathrm{kN}]\end{array}$} & \multirow{2}{*}{$\begin{array}{c}\text { Presumed breaking } \\
\text { load }[\mathrm{kN}]\end{array}$} & \multirow{2}{*}{$\begin{array}{c}\text { Equipment } \\
\text { No. }\end{array}$} & \multicolumn{4}{|c}{ Moving load [kN] } \\
\cline { 3 - 7 } & \multirow{2}{*}{80} & \multirow{2}{*}{83.9} & 1st time & 2nd time & 3rd time & Average \\
\cline { 3 - 7 } & \multirow{2}{*}{40} & 2 & 94.5 & 94.7 & 92.4 & 93.8 \\
\hline \multirow{2}{*}{43.5} & 3 & 45.7 & 45.7 & 44.4 & 45.3 \\
\cline { 3 - 7 } & & 4 & 44.0 & 46.4 & 44.5 & 44.9 \\
\hline
\end{tabular}

\section{Dynamic load testing by means of shaking tests on a full-scale bogie}

Shaking tests on a test body installed on the RTRI large shaking test facility (shaking table) were conducted in order to examine normal movement when impact forces, generated by car body and bogie behavior under earthquake conditions, are acting on the crushable stopper, and to verify whether gap expansion actually prevents derailment.

Figure 7 is an outside view of the test model of a Shinkansen half car-body. The mock up comprised rails fixed to the shaking table, a Shinkansen bogie on the rails, a load frame to imitate the car body, and securing link to prevent toppling of the load frame and to restrain motion in the longitudinal, pitching and yawing directions. Weights can be attached on the load frame to simulate arbitrary car body mass, such as the tare mass or gross weight of the car. In this test, the mass of the load frame was set on the assumption that the model car was carrying a maximum number of passengers $(16200 \mathrm{~kg})$. The wheel load was measured by a strain gauge fastened to the rail, directly under each of the 4 wheels.

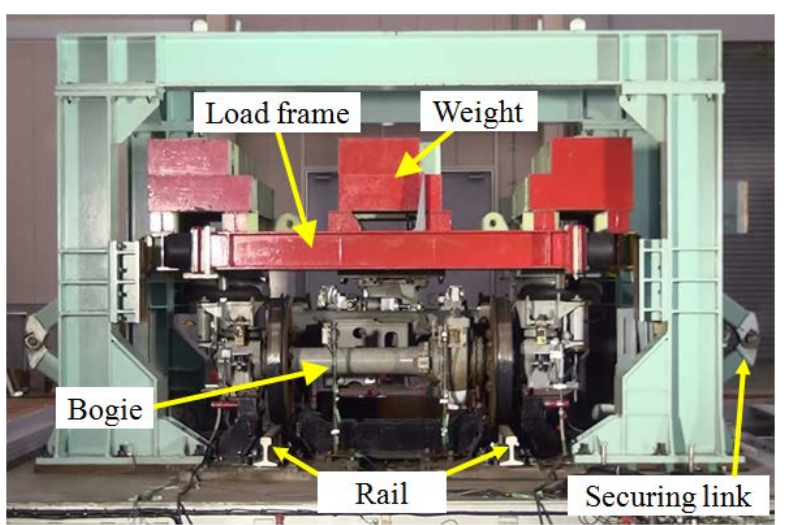

Fig. 7 Mock up comprised rails fixed to the shaking table, a Shinkansen bogie on the rails, a load frame to imitate the car body, and securing link to prevent toppling of the load frame and to restrain motion in the longitudinal, pitching and yawing directions. Weights can be attached to the load frame to simulate arbitrary car body mass, such as the tare mass or gross weight of the car.

\subsection{Stopper gap expansion test}

\subsubsection{Test conditions}

Although stoppers with larger gaps from the center pin are considered to be better for securing running safety in the case of an earthquake with a high frequency component (Miyamoto and Ishida, 2008), this had not been examined experimentally. Hence, prior to examination of the crushable stopper, this assumed effect on improving running safety was confirmed by examining and comparing the remaining wheel load in the case of sinusoidal excitation with a gap fixed at $23 \mathrm{~mm}$ (normal) and at $53 \mathrm{~mm}$ (expanded by $30 \mathrm{~mm}$ ). In addition, since the excitation acceleration in this examination was set at the maximum value under the condition that the impact of the stopper does not exceed the fatigue load limit of the attachment section with its gap fixed at $23 \mathrm{~mm}$, the amplitude and the acceleration differ from one excitation frequency to another.

\subsubsection{Results of the test}

The ratio of the remaining wheel load to the static wheel load (wheel load remaining ratio) for each excitation frequency is shown in Table 2. This table shows the following; there is no significant difference in the wheel load remaining ratio resulting from the gap difference in the case of the excitation frequency with $0.6 \mathrm{~Hz}$ or less, whereas a clear difference can be observed for excitation frequencies of $0.7 \mathrm{~Hz}$ or more. The different gap effects are due to the difference of vehicle behavior according to the excitation frequency (Miyamoto, et al., 1997) (Miyamoto, et al., 1998). 
This confirms that margin of safety from derailment is improved when the gap is large.

Table 2 Relation between the gap and the wheel load remaining ratio by sinusoidal excitation.

\begin{tabular}{c|c|c|c}
\hline \hline \multicolumn{2}{|c|}{ Excitation conditions } & \multicolumn{2}{|c}{ Remaining wheel load / static wheel load [\%] } \\
\hline Frequency [Hz] & Acceleration [gal] & Gap expansion (53mm) & Gap normal (23mm) \\
\hline 0.5 & 130 & 0.0 & 2.6 \\
0.6 & 120 & 0.0 & 0.0 \\
0.7 & 110 & 59.4 & 0.0 \\
0.8 & 140 & 67.6 & 61.9 \\
0.9 & 240 & 60.6 & 49.9 \\
1.0 & 320 & 55.5 & 46.3 \\
1.1 & 420 & 52.8 & 28.1 \\
1.2 & 500 & 59.4 & 40.1 \\
1.3 & 800 & 34.5 & 8.8 \\
1.4 & 500 & 58.2 & 27.8 \\
1.6 & 400 & 69.3 & 27.0 \\
1.8 & 400 & 83.9 & 29.4 \\
2.0 & 500 & 77.4 & 51.0 \\
2.1 & 550 & 71.4 & 63.7 \\
2.2 & 650 & 65.1 & 46.7 \\
2.3 & 750 & 62.8 & 42.0 \\
2.4 & 800 & 61.1 & 51.6 \\
2.7 & 1000 & 60.3 & 45.4 \\
3.0 & 1100 & 68.0 & 61.9 \\
\hline
\end{tabular}

\subsection{Crushable stopper functional verification test}

Figure 8 shows the bogie equipped with the crushable stopper. It is impossible to attach the crushable stopper on the existing stopper seat on the bogie. Therefore, a crushable stopper support base was welded on the connection beam of the bogie frame. This moved the position of the lateral displacement stoppers upwards by about $170 \mathrm{~mm}$ compared with the normal stopper.

The force applied to the lateral displacement stopper was measured by strain gauges attached to the crushable stopper support bases as shown in Fig. 9. Although the strain from the vertical force might be also generated in the crushable stopper support base, the loading in the vertical direction was difficult and only the calibration of the force applied to the lateral displacement stopper was carried out as shown in Fig. 10. Moreover, a reflecting plate was attached to the base plate of the stopper rubber, and the lateral displacement stopper stroke was measured using a laser displacement gauge, as shown in Fig. 11.

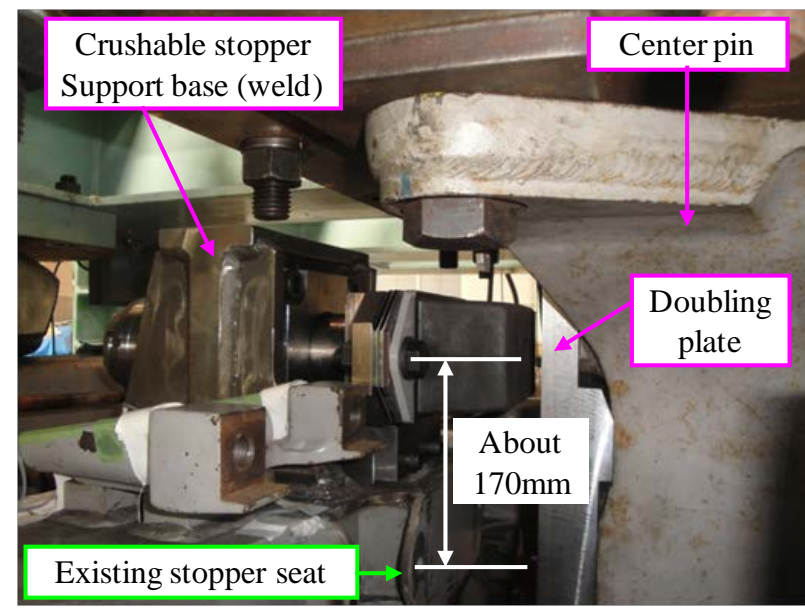

Fig. 8 Crushable stopper support base was welded on the connection beam of the bogie frame. This moved the position of the crushable stopper upwards by about $170 \mathrm{~mm}$ compared with the normal stopper.

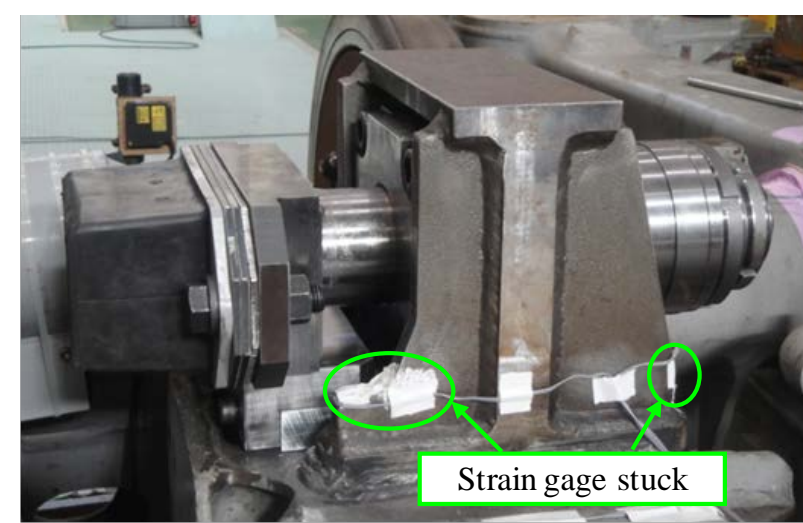

Fig. 9 Force applied to the lateral displacement stopper was measured by strain gauges attached to the crushable stopper support bases. 


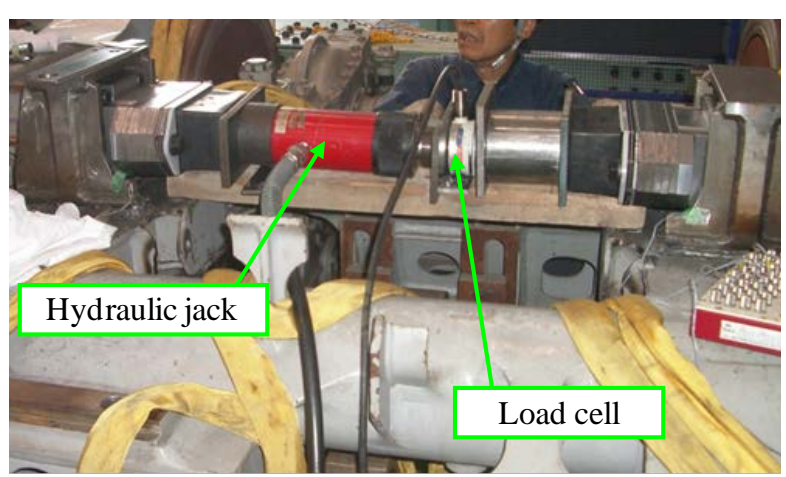

Fig. 10 Calibration of the force applied to the lateral displacement stopper was carried out.

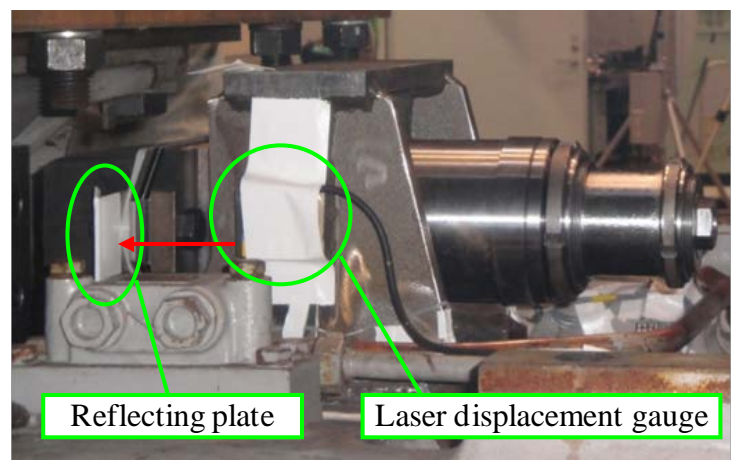

Fig. 11 Lateral displacement stopper stroke was measured by a laser displacement gauge with a reflecting plate.

\subsubsection{Test conditions}

The bogie was excited in the lateral (sleeper) direction by sine wave and seismic wave. Excitation conditions are shown in Tables 3 and 4 for each set moving load. The estimated seismic waveforms which caused derailment in the Mid Niigata Prefecture Earthquake in 2004 (Chuetsu wave) (Simulation Analysis Group for Derailment of Shinkansen in Earthquake, 2008) were used for the seismic wave excitation, changing its magnification. In addition, since the crushable stopper must be used together with a specially designed anti-seismic lateral damper, as mentioned above, all tests to confirm movement reliability and effectiveness were carried out with the specialized lateral damper.

Table 3 Test condition of shaking test (set moving load 40kN).

\begin{tabular}{c|c|c|c|c}
\hline \hline \multirow{2}{*}{$\begin{array}{c}\text { Test } \\
\text { No. }\end{array}$} & \multicolumn{4}{|c}{ Frequency, Acceleration / Waveform, Magnification } \\
\cline { 2 - 5 } & 1st time & 2nd time & 3rd time & 4th time \\
\hline $1-1$ & $1.2 \mathrm{~Hz}, 500$ gal & $1.2 \mathrm{~Hz}, 600$ gal & & \\
\hline $1-2$ & $1.0 \mathrm{~Hz}, 320$ gal & $1.1 \mathrm{~Hz}, 420$ gal & $1.2 \mathrm{~Hz}, 660$ gal & \\
\hline $1-3$ & $0.6 \mathrm{~Hz}, 50$ gal & $0.6 \mathrm{~Hz}, 70$ gal & $0.6 \mathrm{~Hz}, 80$ gal & $0.6 \mathrm{~Hz}, 90 \mathrm{gal}$ \\
\hline $1-4$ & Chuetsu wave, $40 \%$ & Chuetsu wave, $45 \%$ & & \\
\hline
\end{tabular}

Table 4 Test condition of shaking test (set moving load 80kN).

\begin{tabular}{c|c}
\hline \hline Test No. & Frequency, Acceleration \\
\hline $2-1$ & $1.4 \mathrm{~Hz}, 1100$ gal \\
\hline
\end{tabular}

\subsubsection{Results of the test}

The shaking conditions leading to gap expansion and the maximum force applied to the lateral displacement stopper before gap expansion occurred in each case are shown in Table 5.

Table 5 Results of the shaking test.

\begin{tabular}{c|c|c|c}
\hline \hline $\begin{array}{c}\text { Test } \\
\text { No. }\end{array}$ & Set moving load [kN] & Shaking condition & $\begin{array}{c}\text { Maximum force applied to } \\
\text { lateral displacement stopper [kN] }\end{array}$ \\
\hline $1-1$ & 40 & $1.2 \mathrm{~Hz}, 600$ gal & 42.9 \\
\hline $1-2$ & 40 & $1.2 \mathrm{~Hz}, 660$ gal & 45.4 \\
\hline $1-3$ & 40 & $0.6 \mathrm{~Hz}, 90$ gal & 50.0 \\
\hline $1-4$ & 40 & Chuetsu wave, $40 \%$ & 44.5 \\
\hline $2-1$ & 80 & $1.4 \mathrm{~Hz}, 1100$ gal & 113.9 \\
\hline
\end{tabular}

The time history of the force applied to the stopper and the stopper stroke for the 6 second period just before and after the gap expansion movement under the excitation conditions in No.1-2 (sine wave $1.2 \mathrm{~Hz}, 660$ gal) in Table 5 is shown in Fig. 12. It is clear that the gap was maintained as long as the force applied to the mechanical crushable stopper was under the set moving load, and that when the set moving load was exceeded, the gap expanded according to the force applied to the stopper.

Moreover, the comparison of the time history of the wheel load between the case where the gap of the mechanical crushable stopper expanded and that where it was fixed at $23 \mathrm{~mm}$, on the same excitation conditions as Fig. 12 is shown in Fig. 13. Although the wheel load was zero when the gap was fixed at $23 \mathrm{~mm}$, it is confirmed that the reduction in wheel load variation and an increase of $10.1 \mathrm{kN}$ of the remaining wheel load is due to the gap expansion 
movement of the mechanical crushable stopper. This is equivalent to an increase of $20.3 \%$ in the wheel load remaining ratio.

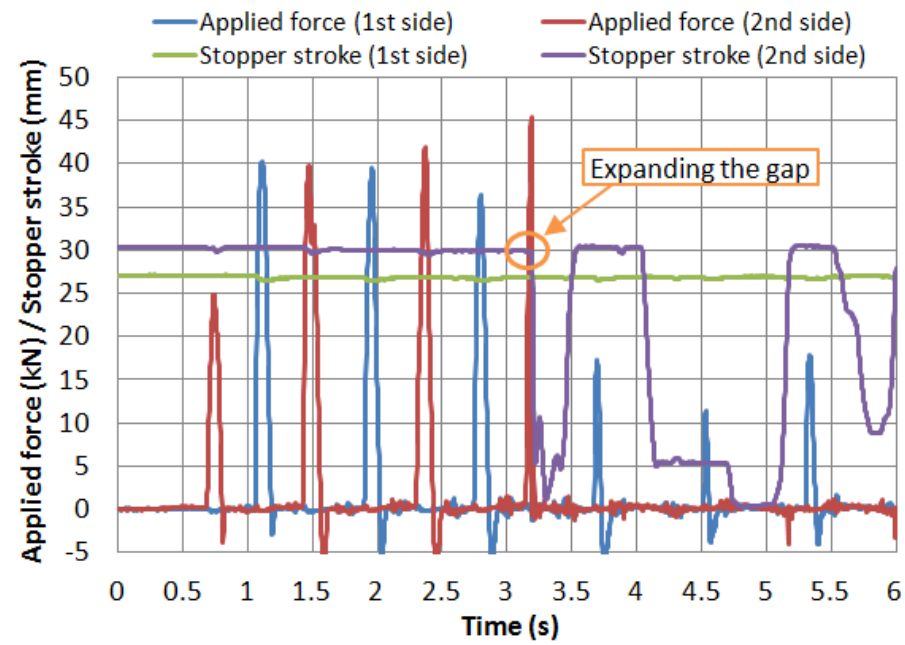

Fig. 12 Time history of the force applied to the stopper and the stopper stroke for the 6 second period just before and after the gap expansion movement under the excitation conditions in sine wave $1.2 \mathrm{~Hz}, 660$ gal

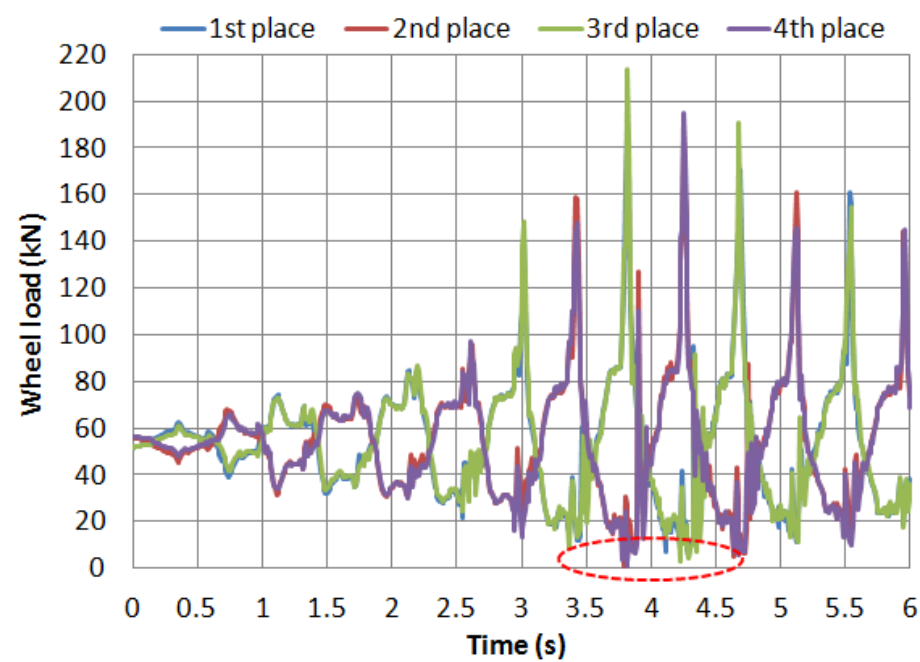

(a) The gap fixed at $23 \mathrm{~mm}$

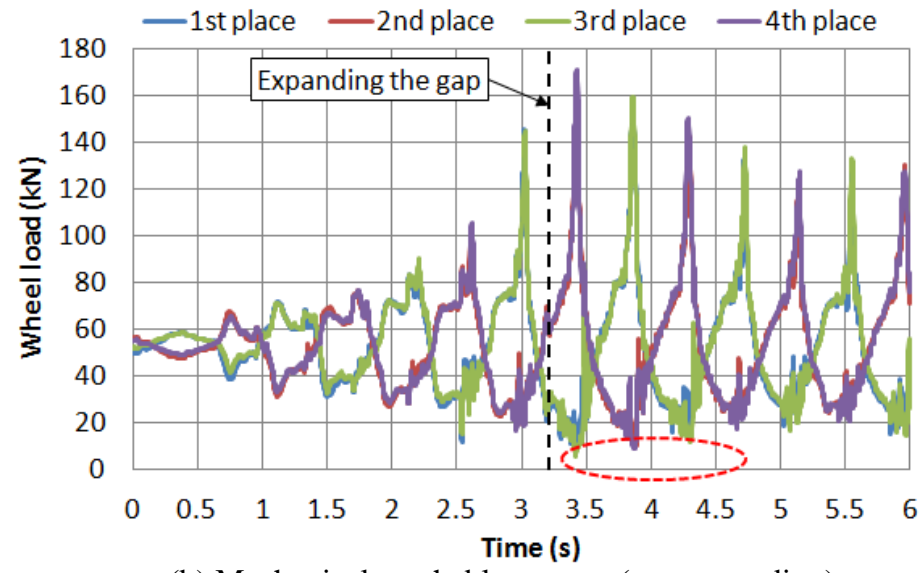

(b) Mechanical crushable stopper (gap expanding)

Fig. 13 Comparison of the time history of the wheel load between the case where the gap of the mechanical crushable stopper expanded and that where it is fixed, on the same excitation condition as sine wave $1.2 \mathrm{~Hz}, 660$ gal

The time history of the force applied to the stopper and the stopper stroke for the 6 second period just before and after the gap expansion movement while being excited to $45 \%$ of the Chuetsu wave is shown in Fig. 14. In the case of seismic wave excitation as well as in the case of sinusoidal excitation, it is proved that the gap is maintained as long as 
the force applied to the lateral displacement stopper is under the set moving load, and that when the set moving load is exceeded, the gap expands according to the force applied to the stopper.

The time histories of the wheel load compared with when the gap of the mechanical crushable stopper expanded, and when it was fixed at $23 \mathrm{~mm}$ under the same conditions as in Fig. 14, are shown in Fig. 15. Although the wheel load is zero in the case of the gap with $23 \mathrm{~mm}$, confirmation is obtained of a fall in wheel load variation and increase in the remaining wheel load of $10.9 \mathrm{kN}$ due to the gap expansion movement of the mechanical crushable stopper. This is equivalent to an increase of $18.2 \%$ in the wheel load remaining ratio.

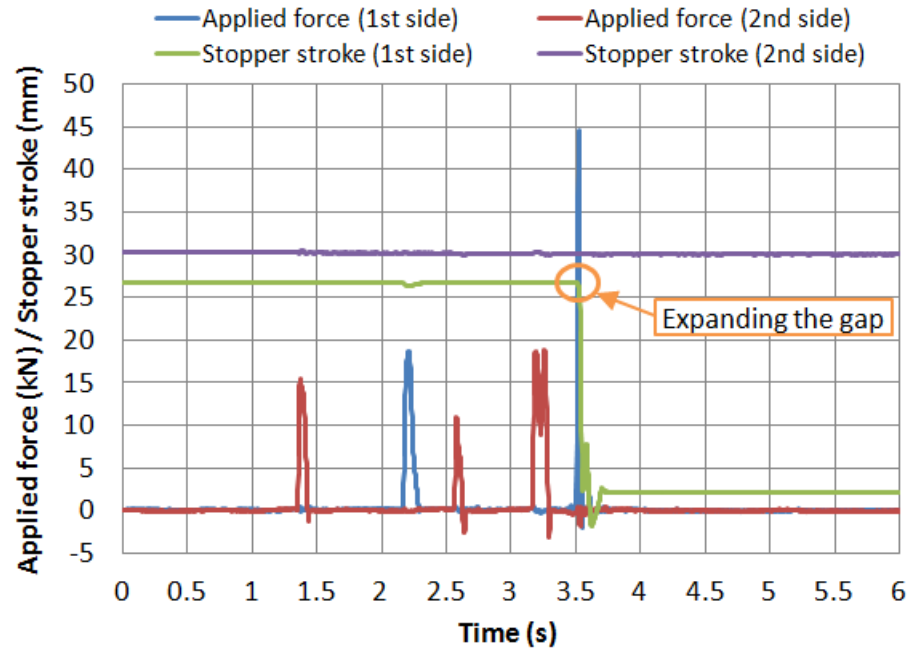

Fig. 14 Time history of the force applied to the stopper and the stopper stroke for the 6 second period just before and after the gap expansion movement while being excited to $45 \%$ of the Chuetsu wave

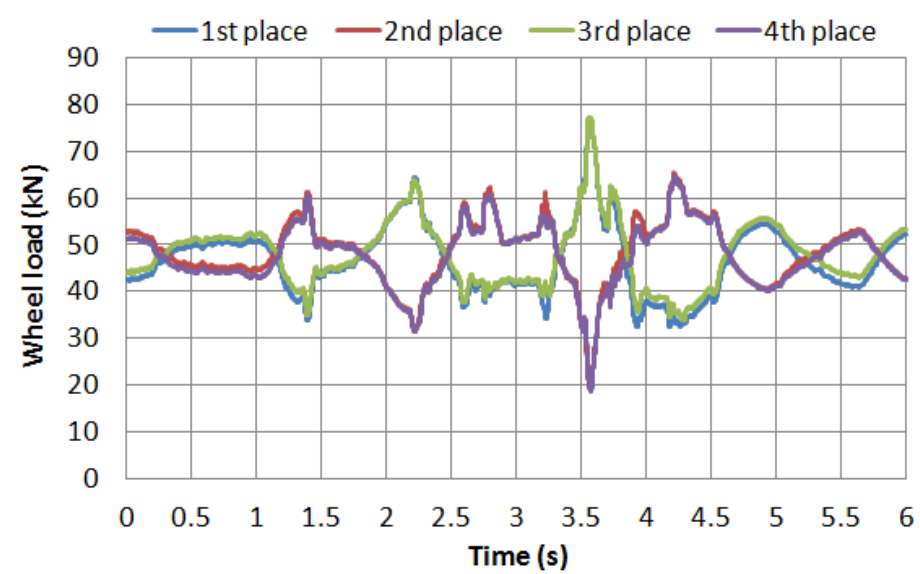

(a) The gap fixed at $23 \mathrm{~mm}$

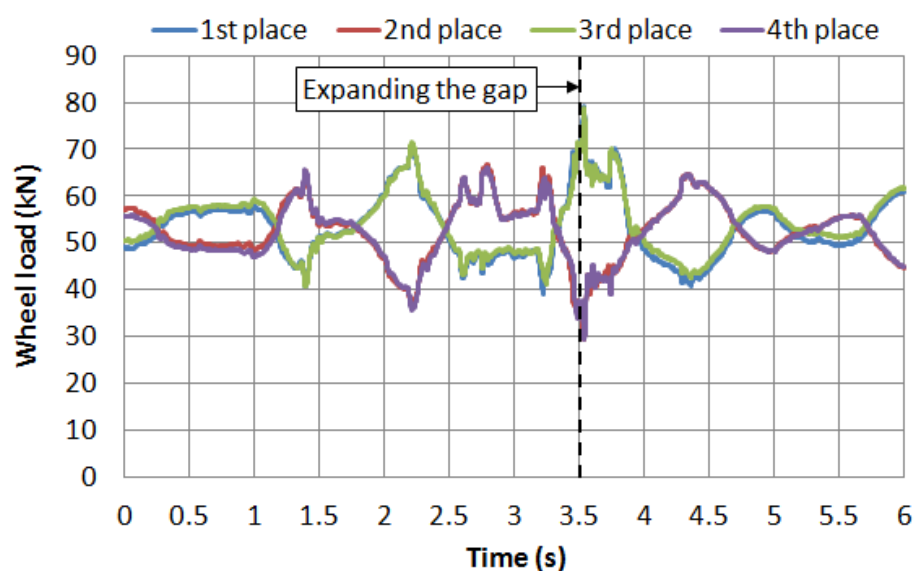

(b) Mechanical crushable stopper (gap expanding)

Fig. 15 Comparison of the time history of the wheel load between the case where the gap of the mechanical crushable stopper expanded and that where it is fixed, on the same excitation condition as the Chuetsu wave $45 \%$ 


\section{Repeated loading test}

For practical application of crushable stopper, it is necessary to ensure the reliability so that its normal movement can be maintained within the inspection period of a bogie. However, as there is a possibility that the daily phenomenon like degradation of the mechanical fuse by the impact during a usual operation may affect the stopper gap expansion movement, the examination about such phenomenon is required.

Then, the load generated by the impact during a usual operation and its frequency were assumed and the repeated loading test was carried out in order to investigate the soundness of the mechanical fuse after applying repeatedly the assumed load and frequency. In this test, as shown in Fig. 16, the crushable stopper was installed in the universal material testing machine, and after repeated loading of the predetermined force, the force necessary for gap expansion movement was examined by gradual loading.

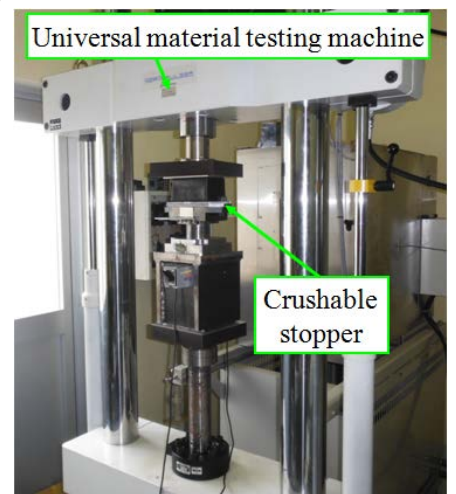

Fig. 16 Crushable stopper was installed in the universal material testing machine, and after repeated loading of the predetermined force, the force necessary for gap expansion movement was examined by gradual loading.

\subsection{Test condition}

Force which executes repetition loading was set to $20 \mathrm{kN}$ which is equivalent to $0.1-0.2 \mathrm{G}$ of the car body mass. This force is the assumed impact during usual operation. This value is equivalent to $25 \%$ of $80 \mathrm{kN}$, set moving load of crushable stopper. However because the set moving load at the time of practical application is larger than $80 \mathrm{kN}$, the rate of the force to the set moving load will become a smaller value than this value, and a setup is on the side of safety. Moreover, as for the number of times of a repetition, the presumed number of times of the stopper impact per day was integrated by the period equivalent to the inspection period of a bogie. Here, the number of times of the stopper impact per day was presumed to be 70 times and 1 inspection period of a bogie was presumed to be 500 days. Accordingly, the number of times of the stopper impact per inspection period of a bogie was presumed to be 35000 times.

\subsection{Results of the test}

For the period which is equivalent to at least 3 times of general inspection period of a bogie, there was no noticeable change of moving load as shown in Fig. 17. From this result, the influence of the repeated loading during usual operation on the moving load is sufficiently small at least within the range of a bogie inspection period.

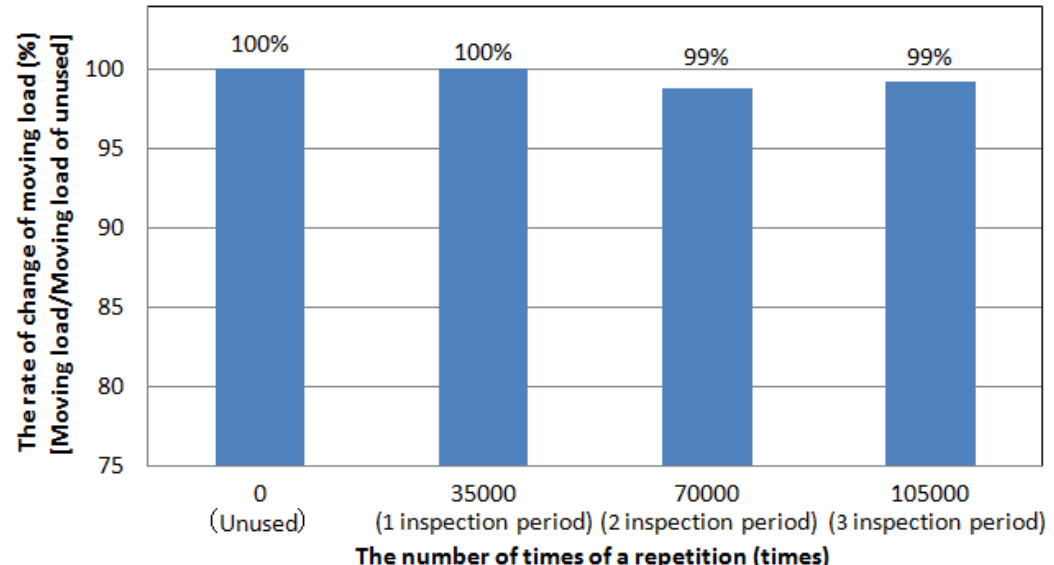

Fig. 17 . For the period which is equivalent to at least 3 times of general inspection period of a bogie, there was no noticeable change of moving load. 


\section{Conclusions}

For the purpose of improving running safety during earthquakes, a crushable lateral displacement stopper was developed, which is designed to be used together with specially designed anti-seismic lateral dampers. The gap between the developed crushable stopper and the center pin is the same as currently-used stoppers, in nominal position, but can expand on impacts, which arises during major earthquakes. Two prototype sets of mechanical crushable stoppers were built including mechanical fuses attached to the movement mechanism, one with a set moving load of 40 $\mathrm{kN}$ and the other of $80 \mathrm{kN}$. These prototypes were used to confirm stability of movement under static load tests and the movement itself under shaking tests on a full-scale vehicle model consisting of one bogie and a half car body on a large shaking test facility. In addition to it, repeated loading test was carried out in order to confirm the influence of the repeated loading during usual operation. The results can be summarized as follows.

(1) Although the $80 \mathrm{kN}$ set moveable load is larger than the presumed breaking load by about ten percent, the dispersion in measured values in both set moving loads of $40 \mathrm{kN}$ and $80 \mathrm{kN}$ is small. These results confirm the stability of the crushable stopper movement. Here, although $40 \mathrm{kN}$ and $80 \mathrm{kN}$ are used as the set moving loads for the purpose of the experiment, the set moving load would in practice have to be adapted to the actual vehicle or relevant earthquake conditions.

(2) The results of sinusoidal excitation tests for the gap fixed at $23 \mathrm{~mm}$ (normal) and $53 \mathrm{~mm}$ (expanded by $30 \mathrm{~mm}$ ), show no significant difference in the wheel load remaining ratio due to the gap difference when the excitation frequency is $0.6 \mathrm{~Hz}$ or less, whereas the wheel load remaining ratio is higher in the case of the larger gap for excitation frequencies of $0.7 \mathrm{~Hz}$ or more. This confirms that the safety from derailment is improved when the gap expands.

(3) The results of the repeated loading test indicate that the influence of the repeated loading during usual operation on the moving load is sufficiently small within the range of 1 bogie inspection period at least.

In the future, similar trials will be conducted in parallel to make progress on the development of a hydraulic crushable stopper. In addition, it is necessary to fix characteristic moving load in consideration of the mass of the car body and assumed seismic motion when the crushable stopper is installed on the bogie.

\section{References}

Iida, K., Suzuki, M. , Miyamoto, T. , Nishiyama, Y. , Nakajima, D. and Kajitani, Y., Development of a lateral damper to improve the running safety of railway vehicles during an earthquake, Quarterly Report of RTRI, Vol.53, No.1 (2012), pp.34-40.

Miyamoto, T. and Ishida, H., Numerical analysis focusing on the running safety of an improved bogie during seismic vibration, Quarterly Report of RTRI, Vol.49, No.3 (2008), pp.173-177.

Miyamoto, T., Ishida, H. and Matsuo, M., Running safety of railway vehicle as earthquake occurs, Quarterly Report of RTRI, Vol.38, No.3 (1997), pp.117-122.

Miyamoto, T., Ishida, H. and Matsuo, M., The dynamic behavior of railway vehicle during earthquake, Transactions of JSME-C, Vol.64, No.626 (1998), pp.236-243 (in Japanese).

Nakajima, D., Suzuki, M. , Nishiyama, Y., Miyamoto, T. and Kajitani, Y., Development of the crushable stopper as bogie parts for countermeasures against derailment in case of earthquake, Proceedings of 7th International Symposium on Speed-up and Sustainable Technology for Railway and Maglev Systems (STECH2015) (2015), Paper No. 1F24

Simulation Analysis Group for Derailment of Shinkansen in Earthquake, RTRI Report, Special No.52: Simulation analysis on derailment of shinkansen vehicles due to the mid Niigata prefecture earthquake in 2004 (2008), p.48, Railway Technical Research Institute (in Japanese). 